\title{
Coupling Between Pecking and Heart Beat in Pigeons
}

Juan D. Delius, Ulrike Lindenblatt and Celia Lombardi

ABSTRACT

The electrocardiogram of pigeons was recorded while they pecked an impact transducer under crossaverages bet ween heart beats and pecks the quasieguil revealed that pecks and heart beats tend to coincide temporally at above chance levels according to patterns that vary from individual to individual pigeon. The mechanisms and the functions of the
coupling are discussed.

INTRODUCTION

Coupling of various qualities between different biological rhythms have been demonstrated in numerous instances (Aschoff, 1981; Hildebrandt and Klein 1979; Koepchen, 1983). In birds for example, a relative locking between respiratory heart beat and wingbeat cycles has been reported (Aulie, 1975; Berger an Hart, 1974). When pecking to ingest a heap of grains while very hungry, when pecking under the control of a partial reinforcement, instrumental conditioning schedule (Delius 1983) or when pecking during a fit induced by the drug apomorphine (Brunelli et al., 1975), this response becomes highly rhythmic in pigeons. Even when pecking is more intermittent it seems to be controlled by an underlying central rhythm of between 2 and $4 \mathrm{~Hz}$ that is then only occasionally expressed in overt responses (Delius, 1985). The beating of the pigeon's heart is an ever present rhythm whose frequency varies between 2 and $6 \mathrm{~Hz}$ depending on the arousal or the exertion state of the subject. Incidental

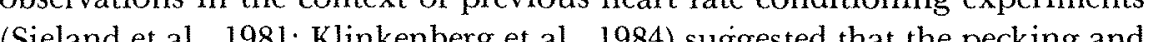
(Sieland ct al., 1981, Klinkenbers et al., 1984) suggested that he pecking and the cardiac activits of pigeons might be loosely locked. Here we report briefly more definite data on the point. To examine the coupling we resorted to the functions frequently used for the analysis of relationships between stochastic signals (Bendat and Piersol 1966). * Experimentelle Tierpsychologie, Psychologisches Institut, Ruhr-Universitäı Bochum, D 4630
Bochum, FRG Konstanzer Online-Publikations-System (KOPS)
URN: http://nbn-resolving.de/unn:nbn:de:bsz:352-20514 


\section{METHOD}

Four adult homing pigeons (Columba livia) of local origin were used. While the pigeons were anaesthetized with an intramuscular injection of a pentobarbital-chloralhydrate mixture (Mallin and Delius, 1983) four stainless steel wire electrodes (each consisting of three strands of $0.1 \mathrm{~mm}$ diameter) were drawn under the two scapular bones and the two pubic spines with the help of a thick, curved hypodermic cannula. The wire ends protruding out of the skin were threaded through four separate lengths of insulating tube brought together on the back of the subject and terminated in a four-pole miniature socket. The animals were first used in another experiment involving classical heart rate conditioning with an atmospheric pressure pulse as a conditioned stimulus and a mildly painful shock as a unconditioned stimulus intended to explore the possible role of the paratympanic (Vitali's) organ in the detection of very low frequency sound (Petrasch et al., 1983; Delius and Emmerton, 1978). When the present experiment began the ECG electrodes had been implanted for some six months and the animals had been experimentally ide for about two months. The pigeons were kept in individual cages $(40 \times 45 \times 40 \mathrm{~cm})$ in a well ventilated, brightly lit (12 h on, $12 \mathrm{~h}$ oll) animal room with ad lib water. evel throughout.

The pigeons were trained to peck a horizontal $25 \mathrm{~mm}$ diameter piezoceramic disk (Valvo) mounted on a heavy metal shelf that replaced the regular feeder on their cages during the conditioning sessions. The transducer signal was gramming nissed a pulse for ser. Cons gramming equipment (Massey-Dickinson) was used to control the reward crains of millet as a reward onto the response disk that was surround by 5 grain hing wall. Each gran delivery was followed by a 1 sec peiod du which fur her operion of the solenoid feder was in a lied chlly all beakcolits the picking up of the reward grain, raised signats hat were reothe chan of an in thumentation tape recorder (Racal). Once the subjects had learned to peck the disk for grain reward they were gradually accusoned to carned fo peck the peck for only occasional rewarts oner several sessions. In sessions that were ratio 10 schedule of renfoent (Delius, 1983). That is, they were rewarded (D) receiving grains for every 10th peck.

The ECG was derived from the left scapular and the right pubic electrodes, the right scapular electrode serving as indifferent. A miniature differential preamplifier of own design mounted on a miniature plug was connected directly to the bird-worn socket Hearing-aid cables, suspended from a rubberband through the cage ceiling, led the signal amplified $10 \mathrm{x}$ to a variable gain 
amplifier (Neurolog), with a passband filter set between 5 and $80 \mathrm{~Hz}$. From there it fed into a second channel of the tape recorder.

The recordings were first checked for freedom from artefacts with a twochannel oscilloscope (Tektronix). Then they were evaluated with a signal averager (Neurolog). The process of averaging as commonly used in neurophysiology (average evoked potentials, see Martin and Venables, 1980) consists in superposing many time sections (sweeps) of one kind of signal (the ECG in our case) in such a way that each and all of the sweeps are overlaid and synchronized with respect to the occurrences of a triggering event (pecks in our case) and then estimating the average time-course of the ECG signal around the trigger events. To implement this procedure the peck signals were fed into an adjustable trigger stage that converted them into standard square pulses of $40 \mathrm{msec}$ duration which initiated the sweeps of the averager. The sweep duration was usually set to $1 \mathrm{sec}$, occasionally to $2 \mathrm{sec}$. The ECG signal was fed into the averager after passing through a $0.5 \mathrm{sec}$, or where appropriate a $1 \mathrm{sec}$, delay line. This meant that the first half of the resulting averages represented the average pre-peck time-course and the second half the average post-peck time-course of the ECG potentials. 256 peck-triggered sweeps were averaged and the average was then written out at a slow speed with a pen recorder (Gould).

This yielded a crossaverage between the electrocardiogram and pecks. To check that the features emerging were not due to chance and since the averager used does not incorporate facilities for statistical evaluation, several ECG/peck crossaverages were computed using different tape record sections from at least two separate recording sessions for each bird. Furthermore we also averaged the ECG with respect to pulses coming from a random pulse generator set to a mean frequency comparable to the peck rate. This control procedure always produced flat, featureless averages. As an additional check for validity we also computed the converse crossaverage where the $\mathrm{R}$ waves of the electrocardiogram were converted through a trigger stage into $40 \mathrm{msec}$ square pulses, initiated the average sweeps and the peck pulse signals of a standard amplitude (see above), after having passed through the delay line, were averaged. The resulting function represents the mean pre- and post-heart beat temporal distribution of pecks. It invariably was an approximate left-right mirror-image of the ECG/peck crossaverages, as one should expect. The differences present were mainly due to the fact that the square peck pulses naturally had a different time-course and thus a different frequency spectrum than the band-limited untransformed heart beat signals. 512 sweeps were needed to clearly reveal the underlying pattern.

Even though inspection of the original records failed to reveal artefacts, in principle it is possible that features associated with the pecks revealed by the $\mathrm{ECG}$ / peck crossaverages could be due to minor signals in the ECG induced by cable capacitance changes or by somatic muscle activity. Such artefacts were circumvented in the last mentioned crossaverages of pecks synchronized upon heart beats as the averager was only triggered by definite $\mathrm{R}$ waves of the ECG. 
The same applies to the converse crossaverages of heart beat pulses on pecks that were also computed. These functions were al ways similar, allowing for the effect of band width mentioned above, to the crossaverages of the straight ECGs and closely analogous, after right-left inversion, to the crossaverages of pecks upon heart beats.

To reveal the periodicity of the pecking and the cardiac activity we also computed separate autoaverages, the quasi-equivalents of the autocorrelation functions, of pecks and of heart beats. This was achieved by separately averaging the same train of peck or beat initiated standard pulses that also served to trigger the averaging sweeps. 64 sweeps sufficed to reveal the underlying patterns in this instance.

\section{RESULTS}

Figure 1 presents in some detail the results pertaining to pigeon 1085. The hear beat autoaverage shows two equispaced and similar peaks before and after the trigger heart beat pulse reflecting the quite regular cardiac rhythm of this subject (about 140 beats per min.), a sample of whose ECG is also shown. The peck autoaverage function similarly evinces two side-peaks but they are less well defined. This has to do with the comparatively low stability of the pecking rhythm in this subject. In particular the peak preceding the trigger events is relatively low indicating that even though the pecks tended to come at regular intervals (about $400 \mathrm{msec}$ ), they did often come in bursts, the averager always triggering on the first response of such series that was naturally not preceded by a peck but mostly followed by further pecks. Note that as revealed by the interval distributions the pecking- and the heart-rhythms do not have exactly the same average frequency and that both show some jitter in their frequency, that is the intervals between the events vary somewhat about the mean. In this
bird such a jitter principally affected the peck rhythm. ird such a jitter principally affected the peck rhythm.

More important, it can be seen that averaging of the ECG synchronized on the peck-responses yields a crossaverage that has obvious features at about the time hat hepecks yields a coscer a trough preceding the peck, a double peak that nearly coincided with the peck, followed by a less pronounced ted itself in different recording samples over several sessions. Crossaverage peraining to two differis se sird The sonverse crossave 1 to document the stability char aves puftes whe averaged synch why this function is not as smooh as the crossaviages of the sy expht ECC

The same comments apply to the directly converse function where heart beat-rigrered pulses, rather than the ECG was averaged synchronized on the 


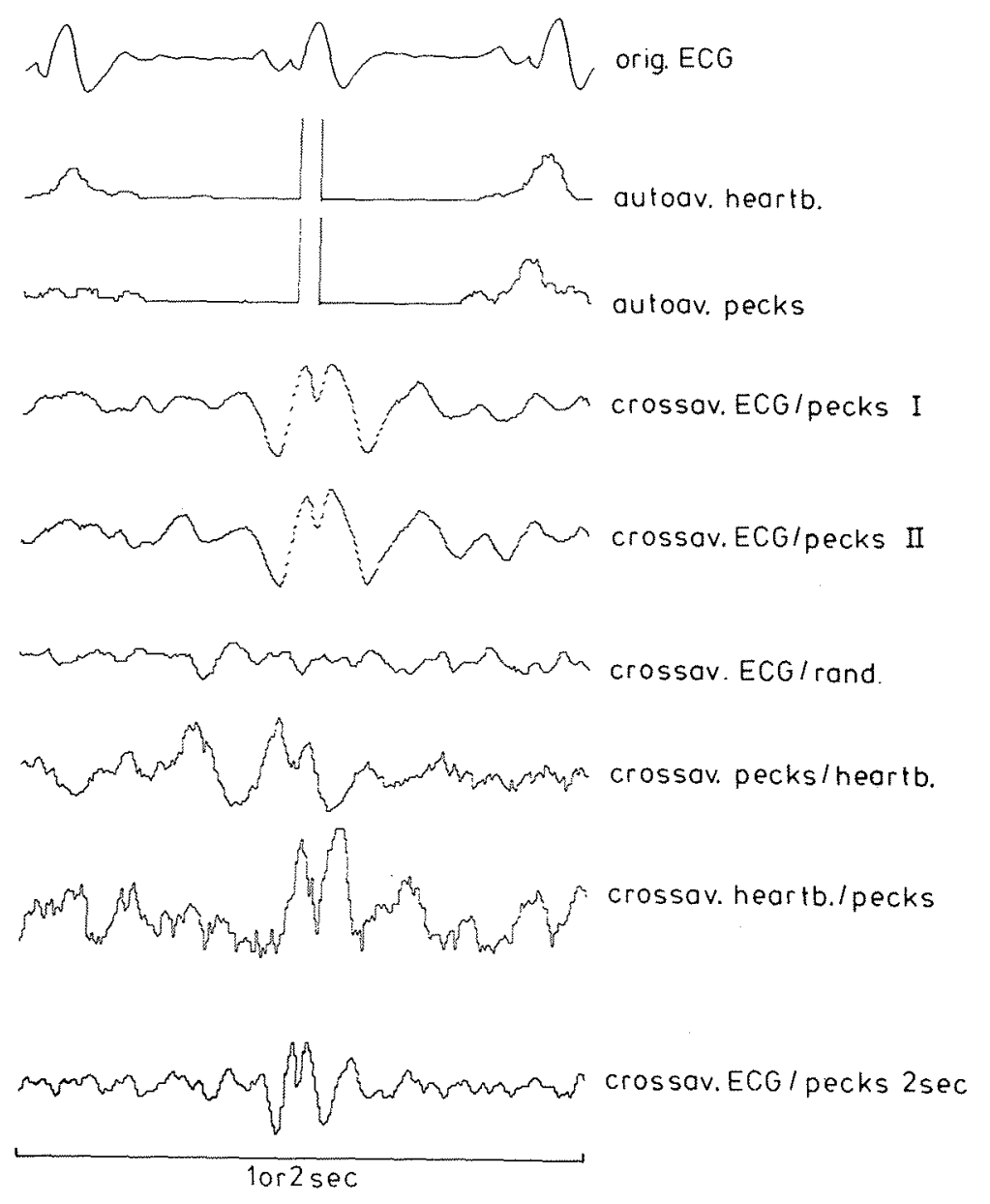

Fig. 1. Pigeon 1085, analog electrogardiogram, autoaverage of heart beats and pecks and crossave-
rages betwer. rages between electrocardiograms or heart beats and pecks or random pulses (control). Here heart
beats stand for standard pulses triggered by the R wave of the ECG. Note the salient features in the beats stand for standard pulses triggered by the $R$ wave of the
middle section of the crossaverage that indicate an above-chance coincidence of the two kinds of
events Tine bese always occurred in the middle of the averages.

pecks. This yielded a crossaverage function that though noisier, reveals much the same main features as the straight computed average. In the instance of pigeon 1085 for example the double main peak temporally close to the peck and the delayed lesser peak is again present showing that it is heart beats, and not any peck related artefacts, that tend to occur in three different modes of locking with pecking. The trough preceding the double peak that is apparent in the ECG based functions appears largely absent in the square pulse derived function indicating that this feature is due to the summation of the $Q$ troughs that 
precede the $\mathrm{R}$ wave of the ECG. We estimated that on average about every fifth heart beat wave fell into one of the three time "slots" corresponding to the crosscorrelogram peaks, the remainder being largely randomly distributed with respect to the pecks. Finally, a longer sweep-duration crossaverage ( $2 \mathrm{sec}$ ) indicates that the crossaverage function becomes increasingly featureless the
further away it is from the peck event. This shows that the coupling between the two rhythms is not periodic, as in fact it can not be, due to the different,
the non-harmonic frequencies of the peck and the heart-rhythms.

Figure 2 displays some of the same information for subject 1134. The autoaverages indicate that in this animal, differently from the previous one the pecking rhythm was more regular than the cardiac rhythm. In fact, the interbeat intervals of this pigeon were remarkably unstable as already illustrated by the short ECG record shown. The crossaverages also reveal a noticeably different patterning than those of subject 1085 . Additionally the peri-peck features, namely the three peaks and two troughs of the crossaverage, are less stable from session to session than those of that bird. Bird 838 yielded yet another pattern, a single peak, heart beats tending to occur clearly in advance of pecks, or rather

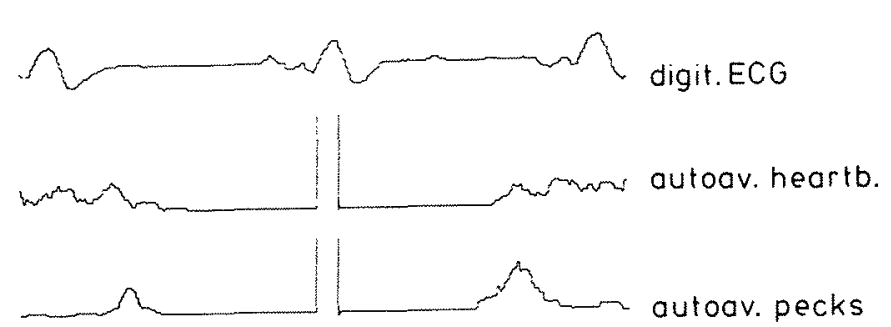

Whan Mand crossaveEG/pecks I

ln $\leadsto$ A crossav.ECG/pecks II

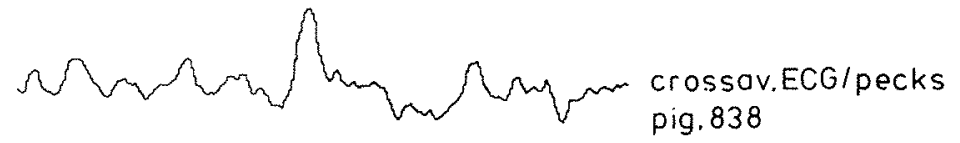

$1 \mathrm{sec}$

Fig. 2. Pigeon 1134, digitized electrocardiogram, autoaverages of heart beats and pecks and pigeon 838 . Note again the peaks in the middle of the crossaverages indicating an above chance coincidence of heart beats and pecks. Time base 1 sec throughout. 
and more precisely, of beak contacts with the force transducer. One must remember that the actual peck movement of course begins some time, about 100 msec before substrate impact, as documented for example by Smith (1974).

The crossaverage functions of bird 956 (not shown) evinced a single peak quite similar to that of bird 838 but the heart beats tended to coincide more closely with the transducer contact. However, while the coupling revealed by the crossaverage features was quite invariant across several recording samples
in the case of pigeon 838 , it was more variable in the case of pigeon 956 , con sam six analysed.

DISCUSSION

The results of the present experiment confirm that there is indeed frequently a relative coupling between pecks and heart beats in pigeons. This does not imply that each peck is associated with a heart beat. Such an absolute locking is not possible as the pecking and the cardiac frequencies are different. Rather it whenever one event is due to occur in the temporal neighbourhood of the other, they shift into some pattern of conjunction. Von Holst (1939) observed a similar kind of phenomenon in locomotory finbeat thythms of fish and aptly described it as a "magnet" effect. It is as if, when two events are about to fall into temporal proximity due to their own and different rhythms, they attract each other so that they coincide. Whether this attraction is mutual, symmetric or not (in the sense for example that only pecks can draw the heart beats but not conversely) we could not decide. A more sophisticated analysis of extended samples beyond our present capabilities will be necessary to resolve this issue. Our impression for what it is worth was that the coupling largely comes about by pecks drawing heart beats.

Little can be said about the physiological mechanisms responsible for the coupling. It is reasonably well documented for mammals (Cohen and Obrist 1975) that motor efferences to the somatic musculature originating centristly coactivate the intracardiac rhythm generator through collateral innervation of coactivate the intracardiac rhythm generator through collateral innervation of the autonomic system. Thus the additional blood supply to the musculature
functionally required by behavioural action is ensured in advance of the actual functionally required by behavioural action is ensured in advance of the actual influence on the cardiac frequency. But a phasic beat by beat influence is not excluded by the existing evidence. In this context it is worthwhile to draw attention to the fact that the central nervous control over the cardiac rhythm in birds seems to be more elaborate than in mammals (Sturkie, 1976). Conversely, there is no evidence for a mechanism by which the cardiac rhythm could control pecking on an event by event basis, unless blood pulse activated neurons can drive neural substrates initiaing pecking motor commands. According to our experience in another context (Delius and Vollrath, 1973; Vollrath and Delius, 1976; see also Sandman et al., 1984) such neurons oceasionally do occur in various regions of the pigeon's central nervous system. 
The coupling between heart beats and pecking varies appreciably in patter ning between individuals. Perhaps this reflects the pronounced plasticity of cardiac control mechanisms that seems to be characteristic for pigeons (Cohen, 1980; Sieland et al., 1981; Klinkenberg et al., 1984). The variability suggests tha the coupling between pecking and heart beating does not fulfil a specific function but that it rather reflects a tendency inherent to biological rhythms to

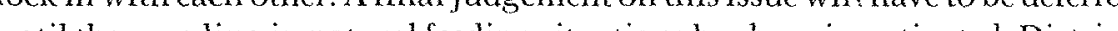

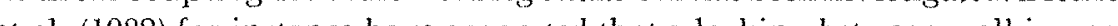
et al. (1982) lor instin have sugsested has a loking betwen walking an

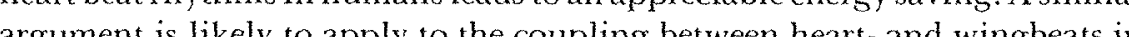
birds. More geneally the coupling of the pecking and hert hy the is an example of te mutual dy comic facilitory exanple of the the timing of of these responses is brought (D) affected (Staddon, 1977).

ACKNOWLEDGEMENTS The research was supported by the Deutsche Forschungsgemeinschaft through its Sonderfor
schungsbereich 1144 , We thank T. Schinauer, A. von Uslar, F. Münchow-Pohl, D. Hagenkötter, A of various kinds.

\section{REFERENCES}

ISCHOFF, J. (ed.) (1981). Handbook of Behavioral Neurobiology, Biological Rhythms. Plenum, New York.
AULIE, A. (1975). Two respiratory patterns in the budgerigar during flight at different ambient temperatures. Comp. Bichem. Physiol. 524, 81-84.
BENDAT, I. S. \& PIERSOL, A. G. (1966). Measurement and Analysis of Random Data. Wiley New York.
BERGER, M., and HART, J. S. (1974). Physiology and energetics of flight. In: Avian Biology Vol BERGER, M.. and HART, J. S. (1974). Physiology and energetics of flight. In: Avian Biology Vo king in the pigeon. Arch. ital. Biol. 113, 303-325,

COHEN, D. H. (1980): The funcitional neuroanatomy of a conditioned response. In: Neura cks \& V. B. Shurykov) pp. 283-302. Ac COHEN, D. H., and OBRIST, P. A. (1975). Interactions betwe, New York. system. Circul. Res. 37, 693-706.

A DELIUS, J. D. (1983). Learning. In Physiology and Behaviour of the Pigeon (edited by M. Abs)

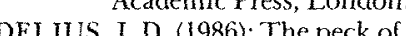
ary Psychology (edited by C. F. Lowe, M. Richelle, D. E. Blackman, and C. M Bradshaw). Errbaum, Hillsdale, New Jersey.

DELS, J. D., and Migation Keeteong) pp. 35-4l. Springer, Berlin 
DELIUS, J. D., and VOLLRATH, F. W. (1973). Rotation compensation reflexes independent of the labyrinth: neurosensory correlates in pigeons. J. Comp. Physiol. 83, 123-124.

DIETRICH, J., RASCHKE, F., \& HILDEBRANDT, G. (1982): The coordination between walking rhythm and heart beat in trained and untrained humans. Plügers Arch. Ges. Physiol. 392 Suppl., R 29.

HILDEBRANDT, G., \& KIEIN, H. R. (1979). Uber die Phasenkoordination von mütterlichem und fötalem Herzrhy thmus während der Schwangerschaft. Klin. Wochenschr. 57, 87-91.

HOLST VON, E. (1939). Die relative Koordination als Phänomen und als Methode zentralnervöser Funktionsanalyse. Ergeb. Physiol. 42, 228-306.

KLINKENBERG, T., DELIUS, J. D., and EMMERTON, J. (1984). Classical heart-rate conditioning and differentiation of visual CS with an appetitive UCS in pigeons. Behav. Processes 9, 23-30.

KOEPCHEN, H. P. (1983). Respiratory and cardiovascular "centres": functional entities or separate structures? In Central Neurone Environment (edited by M. E. Schläfke, H. P. Koepchen, \& W. R. See) pp. 221-237. Springer, Berlin.

MALLIN, H. D., \& DELIUS, J. D. (1983): Inter- and intraocular transfer of colour discriminations with mandibulation as an operant in the head-fixed pigeon. Behav. Anal. Lett. 3, 297-309.

MARTIN, I., \& VENABLES, P. K. (eds.) (1980). Techniques in Psychophysiology. Wiley, Chichester, New York.

PETRASGH, E. W., ANDRES, K. H., VON DÜRING, M., \& DELIUS, J. D. (1983). Morphologische Aspekte des Vitali-Organs bei der Taube. Anat. Anz. Bd. 153, 288.

SANDMAN, C. A., O'HALLORAN, J. P., \& ISENHART, R. (1984). Is there an evoked vascular response? Science 224, 1355-1357.

SIELAND, M., DELIUS, J. D., RAUTENBERG, K., \& MAY, M. (1981). Themoregulation mediated by heart-rate changes in pigeons. J. Comp. Physiol. 144,375-379.

SMITH, R. F. (1974). Topography of the food reinforced key peck and the source of 30 -msec interresponse times. J. exp. Anal. Behav. 21, 541-551.

STADDON, J. E. R. (1977). Schedule-induced behavior. In Handbook of Operant Behavior (edited by W. K. Honing, \& J. E. R. Staddon) pp. 125-152. Prentice-Hall, Englewood Cliff, New Jersey.

STURKIE, P. D. (ed.) (1976). Avian Physiology. Springer, Berlin.

TARPY, R., \& DELIUS, J. D. (1974). Stimulus control of heart rate by auditory frequency and auditory pattern in pigeons. J. Exp. Anal. Behav. 21, 297-306.

VOLLRATH, F. W. \& DELIUS, J. D. (1976). Vestibular projections in the thalamus of the pigeon. Brain, Behav. Evol. 13, 58-68. 